\title{
Competition induces increased toxin production in toad larvae without allelopathic effects on heterospecific tadpoles
}

\author{
Veronika Bókony $^{1}$ (D) | Bálint Üveges ${ }^{1}$ (D) | Ágnes M. Móricz ${ }^{2}$ | Attila Hettyey ${ }^{1}$ (D)
}

${ }^{1}$ Lendület Evolutionary Ecology Research Group, Plant Protection Institute, Centre for Agricultural Research, Hungarian Academy of Sciences, Budapest, Hungary

${ }^{2}$ Department of Pathophysiology, Plant Protection Institute, Centre for Agricultural Research, Hungarian Academy of Sciences, Budapest, Hungary

\section{Correspondence}

Veronika Bókony

Email: bokony.veronika@agrar.mta.hu

\section{Funding information}

Hungarian Academy of Sciences, Grant/ Award Number: LP2012-24/2012; Marie Curie Career Integration Grant, Grant/Award Number: PCIG13-GA-2013-631722; National Research, Development and Innovation Office, Grant/Award Number: 115402

Handling Editor: Anthony Herrel

\section{Abstract}

1. Inducible defences are a form of phenotypic plasticity by which organisms respond to and mitigate the threat posed by predators, parasites and competitors. While anti-predatory defences are often in trade-off with anti-competitor responses, chemicals that deter predators may have negative effects on competitors as well. Allelopathy is well known in plants and plant-like animals, but whether the toxins of mobile, behaviourally and morphologically complex animals are induced by and exert allelopathic effects on competitors is poorly known.

2. Common toads Bufo bufo synthesize bufadienolides which make them unpalatable or toxic to many predators. However, bufadienolide content of toad tadpoles correlates positively with the density of competitors in natural populations, suggesting that they may upregulate their toxin production to inhibit their competitors, such as heterospecific tadpoles that may be vulnerable to toad toxins.

3. We conducted a microcosm experiment with tadpoles of common toads and agile frogs Rana dalmatina, in which we manipulated the density of conspecific and heterospecific competitors. We measured the bufadienolide content of toad tadpoles to test for competitor-induced changes in toxin production, and we assessed the growth and development of agile frog tadpoles to test for allelopathy.

4. We found that toad tadpoles contained higher amounts of bufadienolides at higher densities; however, heterospecific competitors did not have a stronger effect than conspecifics. Furthermore, the presence or density of toad tadpoles had no effect on the body mass and development rate of agile frog tadpoles.

5. Our results demonstrate competitor-induced plasticity in toxin production, but we found no support for an allelopathic function of bufadienolides. Instead, we suggest that inducible changes in bufadienolide production may serve to mitigate risks posed by competitors, including aggression, cannibalism or disease. Therefore, bufadienolides are intriguing candidates for multi-purpose defences that may provide protection not only against predators but also against competitors.

\section{KEYWORDS}

allelopathy, amphibian toxins, chemical defence, chemical interference, growth inhibition, growth-defence trade-off, inducible defences, phenotypic plasticity 


\section{1 | INTRODUCTION}

In response to the risk posed by natural enemies, many organisms including animals and plants produce altered phenotypes that provide protection against those enemies; this form of phenotypic plasticity is referred to as inducible defence (Adler \& Harvell, 1990; Tollrian \& Harvell, 1999). It occurs in diverse taxa in many forms, including changes in body shape that reduce palatability or enhance escape ability, behavioural responses that reduce the encounter rate with or detectability to predators, and accumulation of repellent or toxic chemicals (Adler \& Harvell, 1990; Hettyey, Tóth, \& Van Buskirk, 2014; Tollrian \& Harvell, 1999). So far, the majority of research on inducible defences has focused on the effects of predators (not counting the extensive research on immune responses to pathogens), demonstrating that predator-induced phenotypic changes are ubiquitous and effective means of enhancing the survival of prey (Adler \& Harvell, 1990; Hettyey, Vincze, Zsarnóczai, Hoi, \& Laurila, 2011; Relyea \& Auld, 2005; Tollrian \& Harvell, 1999; Van Buskirk, 2002). However, predators are not the only kind of enemies that organisms need to fend off; competitors can also have large effects (Connell, 1983; Gurevitch, Morrow, Wallace, \& Walsh, 1992). The adaptive responses against competitors are often in trade-off with the adaptive responses against predators: for example, behavioural and morphological changes that are beneficial in competition, such as elevated foraging activity and larger intestines which facilitate growth, expose individuals to higher predation risk (Relyea, 2002; Relyea \& Auld, 2004, 2005; Tollrian \& Harvell, 1999). Chemical defences are particularly intriguing in this respect because they may be multi-functional in the sense that a single phenotype may provide protection against several types of enemies (Hettyey et al., 2014). For example, in plants and soft corals, the defensive chemicals can have both anti-predatory and anti-competitor effects (Kubanek et al., 2002; Siemens, Garner, Mitchell-Olds, \& Callaway, 2002). Understanding such responses whose effectiveness against predators and competitors is not traded off against each other (Ramamonjisoa \& Natuhara, 2017; Siemens et al., 2002) should provide valuable insights into the ecology and evolution of phenotypic plasticity (Hettyey et al., 2014).

In competitive interactions, organisms can use chemical substances that provide advantage by harming their competitors; such substances have been variably termed defensive or offensive chemicals, allelochemicals or allomones (Berenbaum, 1995). Chemical interference or allelopathy can be an effective way of overcoming competitors, especially in sessile organisms like plants, fungi and benthic marine invertebrates (Reigosa, Pedrol, \& González, 2006). The role of allelochemicals in competitive interactions is much less known in mobile animals that can employ a wide diversity of behavioural responses against their foes, although toxins can be found in many of such organisms (Brodie, 2009; Casewell, Wüster, Vonk, Harrison, \& Fry, 2013). Defensive toxins of such animals are thought to function mainly as anti-predatory adaptations, and there is some evidence that they can be induced in prey animals by predation threat (Benard \& Fordyce, 2003; Hagman, Hayes, Capon, \& Shine, 2009) similar to the herbivore-induced chemical responses of primary producers (Tollrian \& Harvell, 1999). However, we know very little about the phenotypic plasticity of toxin production in animals in response to competitors (Adler \& Harvell, 1990; Hettyey et al., 2014).

In this study, we investigated the effect of competition on the toxin production of amphibian larvae, and the allelopathic potential of competitor-induced toxin production. At high densities, amphibian larvae compete for food by both exploitation and interference (Wells, 2007), and chemical interference has long been suspected as a mechanism by which tadpoles can inhibit the growth of their competitors (Crossland \& Shine, 2012; Licht, 1967; Wells, 2007). Despite considerable research effort, however, it is still unclear whether this interference is mediated by specific growth-inhibitor substances, metabolic waste products, or facultative gut parasites such as yeasts or algae (Bardsley \& Beebee, 2001; Griffiths, Denton, \& Wong, 1993; Wells, 2007). Furthermore, it is not clear how tadpoles could inhibit the growth of conspecifics by such substances without suffering from autotoxicity themselves (Wells, 2007), suggesting that chemical interference is more likely to function in interspecific competition, similar to allelopathy among plants (Reigosa et al., 2006) and to the chemical repellents used by ants for deterring heterospecific competitors from food sources (Adams \& Traniello, 1981).

We examined common toads Bufo bufo, which contain toxins that make them distasteful or even lethal upon ingestion or contact (Crossland, Brown, \& Shine, 2011; Henrikson, 1990) or via indirect, waterborne interactions (Crossland \& Shine, 2012; Crossland et al., 2011). Their main toxins are steroid compounds called bufadienolides, which they start to synthesize early during larval development (Üveges et al., 2017). Our earlier studies showed that in common toad larvae, the diversity and quantity of bufadienolides were higher in natural populations with higher competitor density (Bókony et al., 2016) and increased when tadpoles were food-restricted in the laboratory (Üveges et al., 2017); both findings suggested that competition induced toxin production. Toad tadpoles often develop in the same water bodies and live on similar diets as tadpoles of other, non-toxic species, such as agile frogs Rana dalmatina (Bókony et al., 2016; McDiarmid \& Altig, 1999). Because agile frogs usually start to spawn several weeks before toads in Hungary (Hettyey, Török, \& Kovács, 2003) and the tadpoles of the former species grow to larger sizes (Lardner, 2000), toad tadpoles would benefit from inhibiting the growth and development of agile frog tadpoles. Whether such inhibition occurs and whether it is associated with toad toxin levels has not been investigated yet, although other bufonid species were observed to have strong negative effects on other ranid species during larval competition (Alford \& Wilbur, 1985; Licht, 1967). Using the common toad-agile frog system, we investigated competitor-induced toxicity and allelopathy by testing the following predictions: (1) stronger competition induces increased toxin production, (2) heterospecific competitors have a larger effect on toxin production than do conspecific competitors and (3) toxinproducing tadpoles inhibit the growth and development of non-toxic heterospecific tadpoles. We experimentally manipulated the strength of competition and the ratio of conspecific and heterospecific competitors in microcosm communities, mimicking natural conditions of small 
ponds that are the typical larval habitats of these amphibians (Vági, Kovács, Băncilă, Hartel, \& Anthony, 2013).

\section{2 | MATERIALS AND METHODS}

\section{1 | Experimental design}

We raised common toad (henceforth Bufo) and agile frog (henceforth Rana) tadpoles in eight density treatments (Figure 1a) following a response surface design (Inouye, 2001). The densities were chosen to reflect low, medium and high levels of competition based on our previous experience with mesocosm experiments with the two study species (Bókony, Mikó, Móricz, Krüzselyi, \& Hettyey, 2017; Hettyey et al., 2011; Mikó, Ujszegi, Gál, Imrei, \& Hettyey, 2015). Three treatment groups (6B, 12B and 24B) contained only Bufo tadpoles (Figure 1a) to test if the production of bufadienolides is adjusted to the density of conspecific competitors. Three treatment groups contained tadpoles of both species (Figure 1a) to compare the effects of conspecific competitors to the effects of heterospecific competitors on the production of bufadienolides, while keeping the total biomass constant. The relative numbers of the two species in these treatments were designed based on our observation that Rana tadpoles grow up to twice as large as Bufo tadpoles in outdoor mesocosms. Thus, we expected six Bufo larvae plus three Rana larvae (treatment 6B3R) to have similar total biomass as 12 Bufo larvae (treatment 12B). Similarly, we expected six Bufo larvae combined with nine Rana larvae (treatment 6B9R) to have a total biomass similar to that of 12 Bufo larvae combined with six Rana larvae (treatment 12B6R) or 24 Bufo larvae (treatment 24B). The expected ratio of the two species' biomass was 1:1 in treatments 6B3R and 12B6R, while in treatment 6B9R, it was 1:3 (Bufo:Rana). This latter treatment was added for double purpose: to address not only competition-induced toxicity but also allelopathy, because we
FIGURE 1 Schematics of the experimental design (a), and the effects of density treatments on the $M \pm S E$ of tadpole body mass (b, c) and bufadienolides $(d-f)$. Letters above the error bars indicate homogenous subsets after correction for multiple comparisons, i.e. groups marked by different letters differ significantly from each other $(p<.05)$, and letters in brackets indicate marginally non-significant differences (g: $p=.068$, i: $p=.085$, $\mathrm{k}: p=.079, \mathrm{n}: p=.070, \mathrm{o}: p=.078$ ). Asterisks above error bars denote significant differences of Rana from Bufo at the same total number of tadpoles. Note the logarithmic scale on the $Y$ axis in e and f. Symbol colour denotes the tubs' species composition (black: Bufo only, white: Rana only; dark grey: both species, more Bufo than Rana; light grey: both species, fewer Bufo than Rana); symbol shape denotes the species in which the dependent variable was measured (circles: Bufo, squares: Rana, diamonds: all tadpoles) (a)

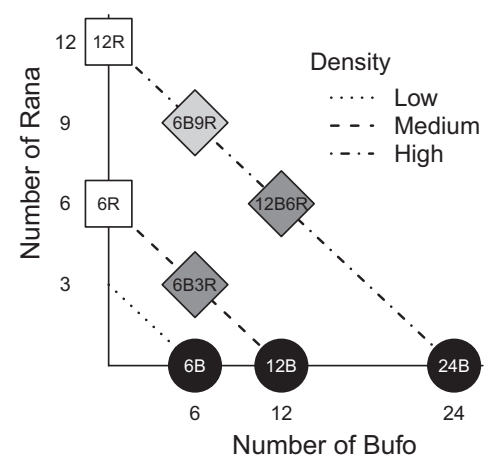

(c)

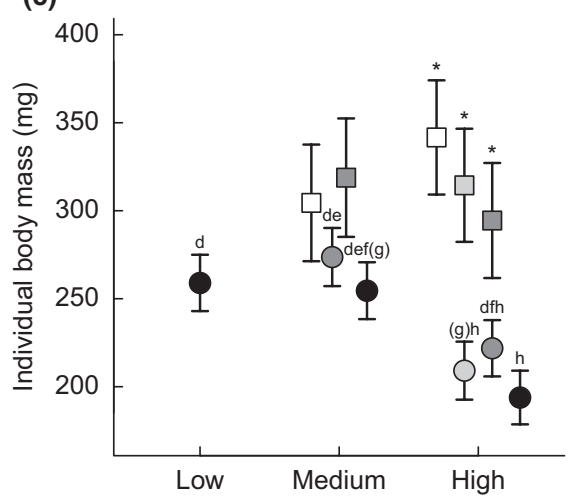

(e)

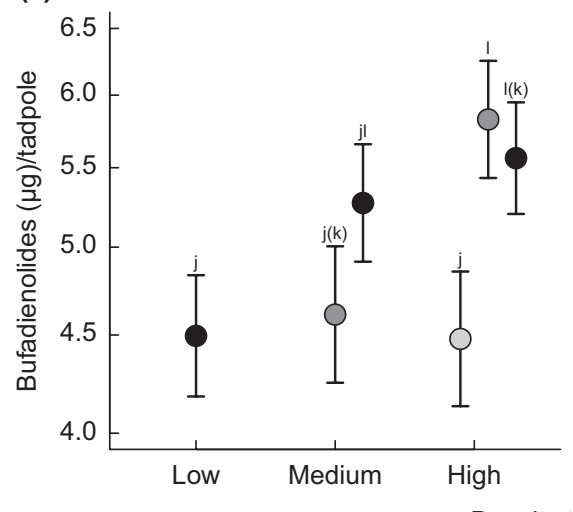

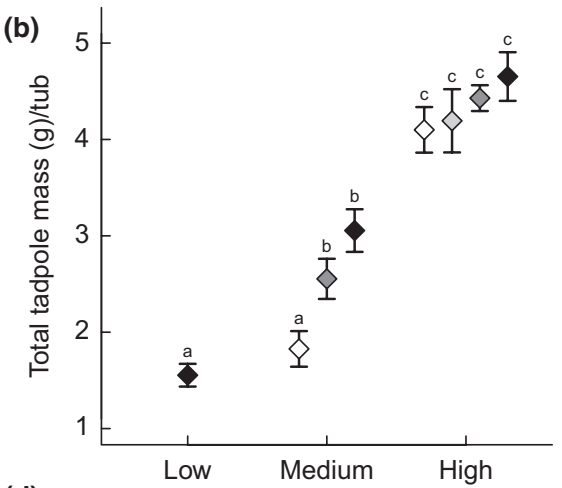

(d)

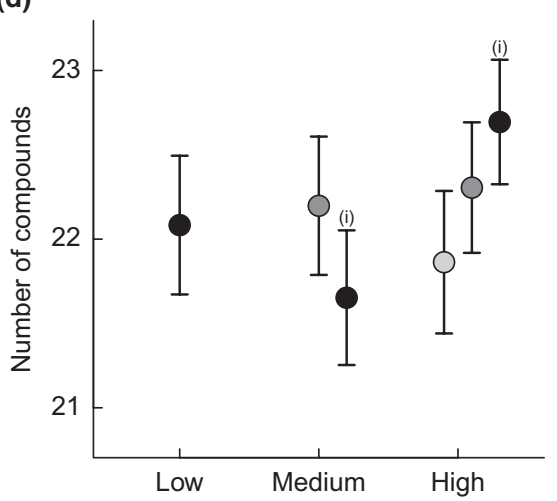

(f)

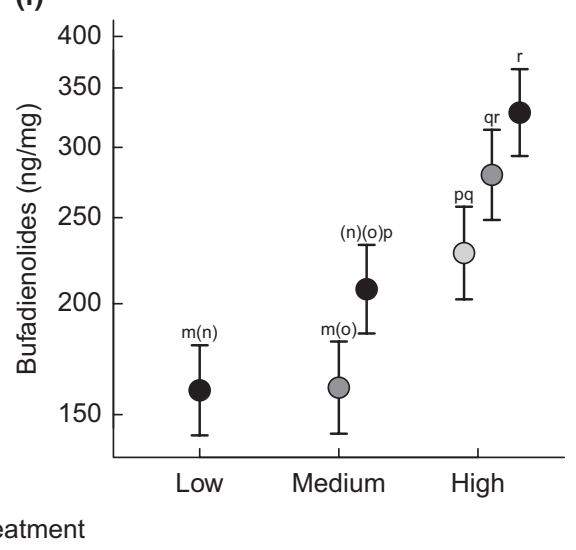


expected that 6 Bufo in treatment 6B9R could produce half as much toxin as 12 Bufo in treatment $12 B 6 R$, so the Rana tadpoles in these two treatments would experience the same total biomass (high density) but different exposure to toxins. Finally, two treatment groups (6R, 12R) contained Rana tadpoles only (Figure 1a), serving as controls for testing whether Bufo tadpoles inhibit the growth and development of Rana tadpoles. There was only one Bufo tadpole missing at the termination of the experiment possibly due to mortality (in treatment 6B3R). Due to an error, nine instead of six Bufo tadpoles were placed in one tub in treatment 6B9R; however, this tub was not an extreme data point in any of the examined variables (in the analyses we treated this tub as if there had been six Bufo in it, to avoid having a treatment group with $n=1$ ). All treatments were started with the same amount of food (see below); we expected the per capita food availability to decrease more in treatments with higher density due to exploitation competition, reducing growth.

\section{2 | Experimental procedures}

In early spring 2016, we collected 60 eggs from each of nine freshly laid Bufo clutches and 30 eggs from each of nine freshly laid Rana clutches from a natural pond in Hungary $\left(47^{\circ} 44^{\prime} 4.12^{\prime \prime} \mathrm{N}, 18^{\circ} 49^{\prime} 7.04^{\prime \prime} \mathrm{E}\right)$. We transported the eggs to the experimental station of the Plant Protection Institute in Budapest, where we kept Bufo eggs in $0.5 \mathrm{~L}$ and Rana eggs in $1 \mathrm{~L}$ reconstituted soft water (RSW; $48 \mathrm{mg} \mathrm{NaHCO}$,

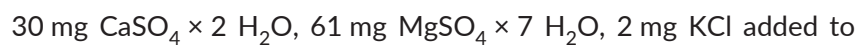
$1 \mathrm{~L}$ reverse osmosis-filtered water). Room temperature was $21^{\circ} \mathrm{C}$ and lighting was set to mimic the natural photoperiod. Right before hatching we transferred embryos in groups of 60 (Bufo) or 30 (Rana) to containers with $5 \mathrm{~L}$ RSW to ensure constant density upon hatching.

Seven weeks before the start of the experiment, we placed $45-\mathrm{L}$ plastic tubs $(56 \times 39 \times 28 \mathrm{~cm})$ in an open outdoor area and filled them with $40 \mathrm{~L}$ tap water. To each tub, we added $0.5 \mathrm{~L}$ pond water (containing phytoplankton and zooplankton) and $20 \mathrm{~g}$ dried beech (Fagus sylvatica) leaves to set up a self-sustaining ecosystem that provides shelter and nutrients for tadpoles. To prevent colonization by predators, we covered the tubs with mosquito net lids. Two days after hatching, we started the experiment by randomly selecting 44 healthy Bufo tadpoles and 24 Rana tadpoles from each family, and placing them into the tubs as follows. For each species, the nine families were divided into three groups of three families each, such that the first Bufo family group was paired up with the first Rana family group and so on. From each family group, we randomly distributed the tadpoles across the eight treatment groups (Figure 1a), with two replicates per family group $\times$ treatment combination, so there were six tubs in each treatment group (two from each family group). In total, we had 48 tubs arranged in six blocks, each block consisting of all treatments of a given family group. This design ensured that each tub contained siblings as well as non-kin tadpoles.

We terminated the experiment after 3 weeks because bufadienolide levels of Bufo tadpoles are highest and most sensitive to environmental conditions around the middle of larval development (Üveges et al., 2017). We weighed all tadpoles to the nearest $0.1 \mathrm{mg}$, and we preserved the Bufo tadpoles $(n=398)$ in HPLC-grade absolute methanol for chemical analysis of bufadienolides. We preserved the Rana tadpoles $(n=216)$ in $50 \%$ ethanol. We identified the developmental stage of all tadpoles according to Gosner (1960) by stereomicroscopic examination (we could not identify the developmental stage of one Rana tadpole because it was deformed).

All experimental procedures were carried out in accordance with Good Scientific Practice guidelines and national legislation. The Ethical Commission of the MTA ATK NÖVI approved the experiment, and the necessary permits were issued by the Government Agency of Pest County, Hungary (PE/KTF/3596-6/2016, PE/KTF/3596-7/2016 and PE/KTF/3596-8/2016).

\section{3 | Chemical analysis}

Each tadpole was homogenized and dried in vacuum to measure dry mass $( \pm 0.1 \mathrm{mg}$ ); then the samples were re-dissolved in $1 \mathrm{ml} \mathrm{HPLC}$ grade absolute methanol and filtered using nylon syringe filters. Quantitative measurement of bufadienolide compounds was carried out by a single-quadrupole HPLC-MS system (Model LC-MS-2020, Shimadzu, Kyoto, Japan) equipped with a binary gradient solvent pump, a vacuum degasser, a thermostated autosampler, a column oven, a photodiode detector and a mass analyser with electrospray ionization (ESI/MS). From each sample, $10 \mu \mathrm{L}$ were injected and analysed at $35^{\circ} \mathrm{C}$ on a Kinetex C18 $2.6 \mu \mathrm{m}$ column $(100 \times 3 \mathrm{~mm}$ i.d.) in series with an octadecyl C18 guard column ( $4 \times 3 \mathrm{~mm}$ i.d.). Eluent $A$ was $5 \%$ aqueous acetonitrile with $0.05 \%$ formic acid and eluent $B$ was acetonitrile with $0.05 \%$ formic acid. The flow rate was $0.6 \mathrm{ml} / \mathrm{min}$ and the gradient was as follows: $0-2 \mathrm{~min}, 10 \%-20 \% \mathrm{~B} ; 2-15 \mathrm{~min}$, 20\%-32\% B; $15-21 \mathrm{~min}, 32 \%-60 \%$ B; $21-21.5 \mathrm{~min}, 60 \%-100 \%$ B; 21.5-26 min $100 \% \mathrm{~B}$; and $26-30$ min $10 \% \mathrm{~B}$. ESI conditions were as follows: interface temperature, $350^{\circ} \mathrm{C}$; desolvation line (DL) temperature, $250^{\circ} \mathrm{C}$; heat block temperature, $400^{\circ} \mathrm{C}$; drying $\mathrm{N}_{2}$ gas flow, $15 \mathrm{~L} / \mathrm{min}$; nebulizer $\mathrm{N}_{2}$ gas flow, $1.5 \mathrm{~L} / \mathrm{min}$; positive ionization mode. Full scan spectra in the range of $\mathrm{m} / \mathrm{z}$ (mass-to-charge ratio) values 350 800 were recorded, and selected-ion monitoring acquisition detecting the base peak of the bufadienolides we previously found in common toads (Bókony et al., 2016; Üveges et al., 2017) was performed as well. Bufadienolides were recognized by their characteristic UV spectrum, and identified by comparing their peak retention time and $\mathrm{m} / \mathrm{z}$ to those of commercially purchased standards and to the peaks present in a toxin sample obtained from juvenile common toads (for more details, see Bókony et al., 2016; Üveges et al., 2017). The data were acquired and processed using LabSolutions 5.42v (Shimadzu).

We detected 24 bufadienolide compounds (Table S1). We used the calibration curve of the bufotalin standard to express the bufotalin-equivalent mass of each bufadienolide compound per sample (Benard \& Fordyce, 2003; Hagman et al., 2009); then we summed the values of all compounds to estimate the total amount of bufadienolides per individual. This variable was then divided by tadpole dry mass to obtain the total amount of bufadienolides per body mass (mass-corrected amount of bufadienolides henceforward). We analysed both variables because they quantify two 
different aspects of toxicity: the mass-corrected amount is more likely to express individual investment (i.e. proportion of resources allocated to toxin production) while the total amount is more likely to be relevant in inter-individual interactions (i.e. total toxin quantity available for allelopathy).

\section{4 | Statistical analysis}

All statistical analyses were run with $\mathrm{R}$ 3.3.1, using the packages "nlme" and "Ismeans". We used two alternative approaches as follows. First, we employed the concept of response surface analysis (Inouye, 2001) to assess how the tadpoles' mass, developmental stage and chemical defence varied with the density of both species. In these models, we assumed linear relationships, entering the number of Bufo and the number of Rana as covariates (numerical predictor variables) along with their interaction. Second, to be able to address potentially non-monotonous or cumulative effects of density, in another set of analyses we used the eight treatments as a fixed factor (categorical predictor variable). In these models, the proportion of variance explained by the treatments was tested using analysis of variance tables (i.e. F-tests) with type-III sums of squares; then, pairwise comparisons among treatment groups were tested by calculating linear contrasts and correcting the $p$-values for multiple testing with the FDR (false discovery rate) method (Pike, 2011).

All analyses were performed with linear mixed-effects (LME) models, in which we allowed for heteroscedasticity across treatment groups (Zuur, leno, Walker, Saveliev, \& Smith, 2009) using the "varldent" function in "Ime" models. When the dependent variable was the total mass of tadpoles per tub, we used family group as a random factor. When the dependent variable was the body mass or developmental stage of individual tadpoles, number of bufadienolide compounds per tadpole, total or mass-corrected amount of bufadienolides, we used tub identity nested in family group as hierarchical random factors. We checked the requirements of LME analysis by inspecting residual plots; we $\log _{10}$-transformed the amount of bufadienolides (both total and mass-corrected) to improve the models' fit. All tests were two-tailed with 95\% confidence level. Our analyses can be reproduced from Bókony, Üveges, Móricz, and Hettyey (2017).

\section{3 | RESULTS}

\section{1 | Competitor biomass}

The total mass of tadpoles per tub varied significantly among treatments $\left(F_{7,38}=88.98, p<.001\right.$, Figure $\left.1 b\right)$. The four high-density treatment groups did not differ among each other but had significantly larger total mass than the four treatment groups with medium or low density (Figure 1b). Also, the low-density group had significantly less total mass than two out of the three medium-density groups (Figure 1b). These differences agree well with our planned grouping of density treatments based on total mass (Figure 1a), except that total mass was smaller than we expected in tubs containing six Rana tadpoles (Figure 1b). This deviation from the planned densities arose because individual body mass did not differ significantly between the two species in the lower density treatments (Figure 1c), whereas at high densities Rana tadpoles had significantly (c. 1.5 times) larger body mass than Bufo tadpoles (Figure 1c).

\subsection{Effects on Bufo}

The body mass of Bufo tadpoles was significantly reduced by highdensity treatments $\left(F_{5,28}=5.25, p=.002\right.$; Figure $\left.1 c\right)$ and decreased with increasing numbers of both conspecific and heterospecific competitors (Table 1). The addition of one Rana was estimated to have about twice as large an effect as the addition of one Bufo (Table 1), suggesting that the effect of competitor biomass per species was similar; however, the effect of Rana was marginally non-significant, whereas the effect of conspecifics was highly significant (Table 1).

We detected 17-24 (most often 21-23) bufadienolide compounds in individual tadpoles (Table S1). While the number of compounds per tadpole showed a marginally non-significant tendency to increase with the number of conspecifics (Table 1), the number of Rana had no significant effect (Table 1) and none of the pairwise differences among treatment groups were significant after correction for multiple testing $\left(F_{5,28}=2.15, p=.089 ;\right.$ Figure $\left.1 \mathrm{~d}\right)$.

In contrast, treatments had highly significant effects on the amount of bufadienolides (total amount per tadpole: $F_{5,28}=4.24, p=.005$; mass-corrected amount: $\left.F_{5,28}=10.65, p<.001\right)$. The total amount of bufadienolides per tadpole was not reduced at high density (Figure 1e), despite the smaller body mass of these tadpoles (Figure 1c). Instead, total bufadienolide amount was explained by a significant interaction between the numbers of Bufo and Rana tadpoles (Table 1, Figure S1): conspecifics had a significant, consistently positive effect while the effect of Rana was marginally non-significant and negative when they were few and increased as their numbers grew (Table 1, Figure S1). As a result, total bufadienolide amount was higher in the two treatments with the largest total mass containing 12 or 24 Bufo than in the three treatments containing six Bufo tadpoles irrespective of total mass (Figure 1e).

The mass-corrected amount of bufadienolides increased gradually with total competitor density (Figure 1f) and increased significantly with the number of conspecifics, whereas the number of Rana had no significant effect (Table 1). These differences in bufadienolide content were not attributable to developmental stage, because there was no significant variation in the developmental stage of Bufo tadpoles among treatment groups $\left(F_{5,28}=1.20, p=.334\right.$; Figure 2$)$ and it was not significantly related to the number of conspecific or heterospecific competitors (Table 1).

\section{3 | Effects on Rana}

The individual body mass of Rana tadpoles did not vary significantly among treatment groups $\left(F_{4,23}=0.56, p=.691\right.$; Figure $\left.1 c\right)$ and was not significantly explained by the number of conspecific or heterospecific competitors (Table 1). Notably, the body mass of six Rana tadpoles was essentially the same when they were raised in the presence 
TABLE 1 Results of response surface analysis testing the effects of Bufo and Rana tadpoles and their interaction

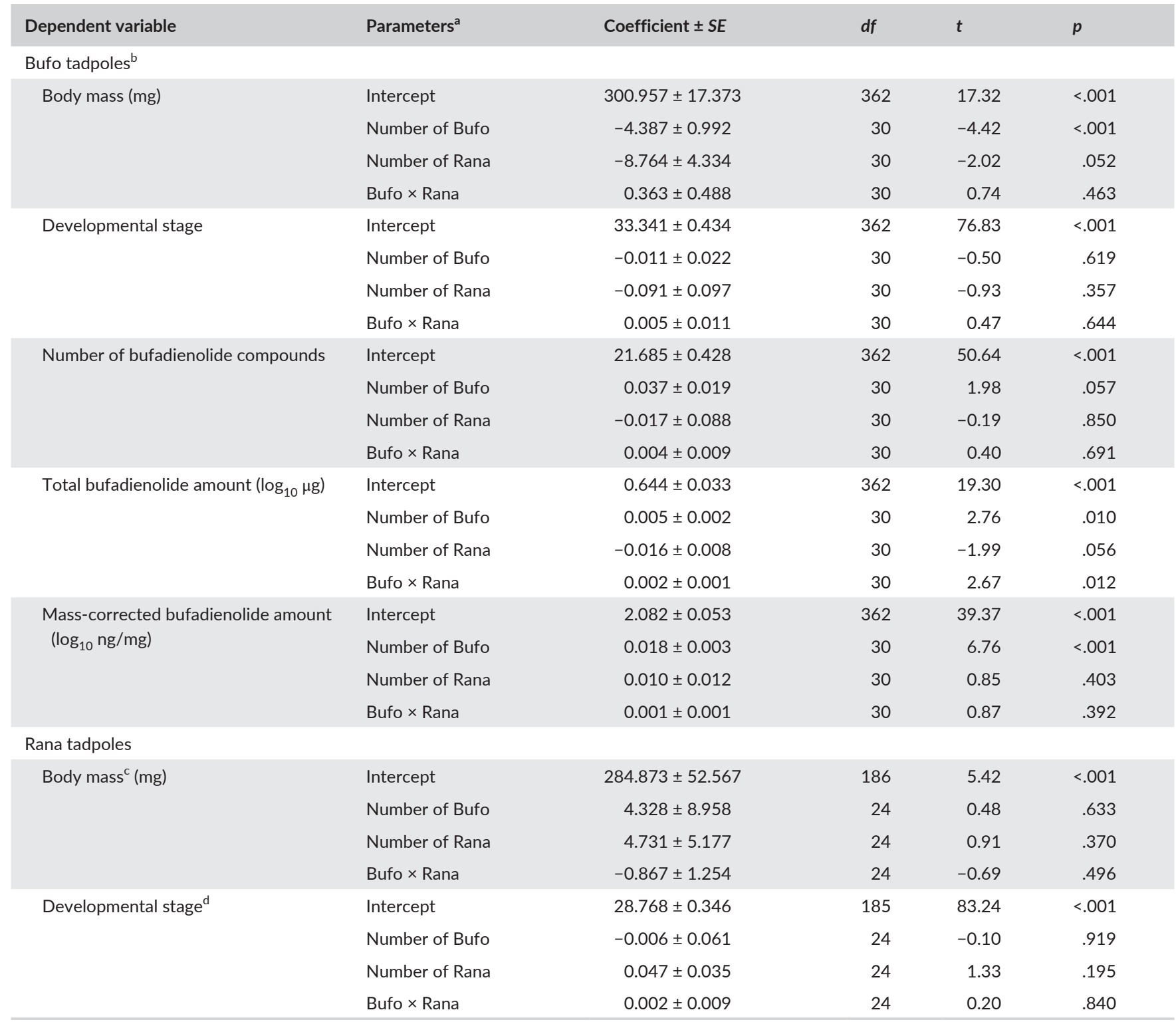

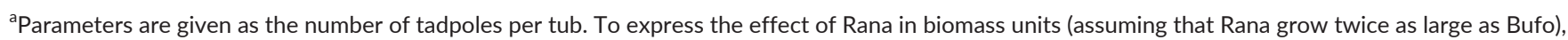
divide the parameters "Number of Rana" and "Bufo $\times$ Rana" by 2.

b398 tadpoles in 36 tubs.

c 216 tadpoles in 30 tubs.

${ }^{\mathrm{d}} 215$ tadpoles in 30 tubs.

or absence of 12 Bufo tadpoles (Figure 1c). Developmental stage showed very limited variation among Rana tadpoles (Figure 2); it did not vary significantly among treatment groups $\left(F_{4,23}=0.90, p=.479\right.$; Figure 2), nor with the number of conspecific or heterospecific competitors (Table 1).

\section{DISCUSSION}

Our study yielded two main results. On the one hand, we found that Bufo tadpoles contained increased quantities of bufadienolides at higher competitor densities, demonstrating competition-induced plasticity in toxin production. On the other hand, we did not find support for the hypothesis that bufadienolides function to suppress heterospecific competitors, because the growth and development of Rana tadpoles was not inhibited by the presence of Bufo tadpoles and also because Rana tadpoles did not induce higher toxin production in Bufo tadpoles than conspecifics did.

To our knowledge, this is the first unequivocal evidence for induced toxin synthesis in response to increased competition in free-moving animals, demonstrating that phenotypic plasticity of chemical defence (or offence) is not limited to predator-prey interactions and immune responses in behaviourally and morphologically complex organisms (Hettyey et al., 2014; Tollrian \& Harvell, 1999). This experimental result 


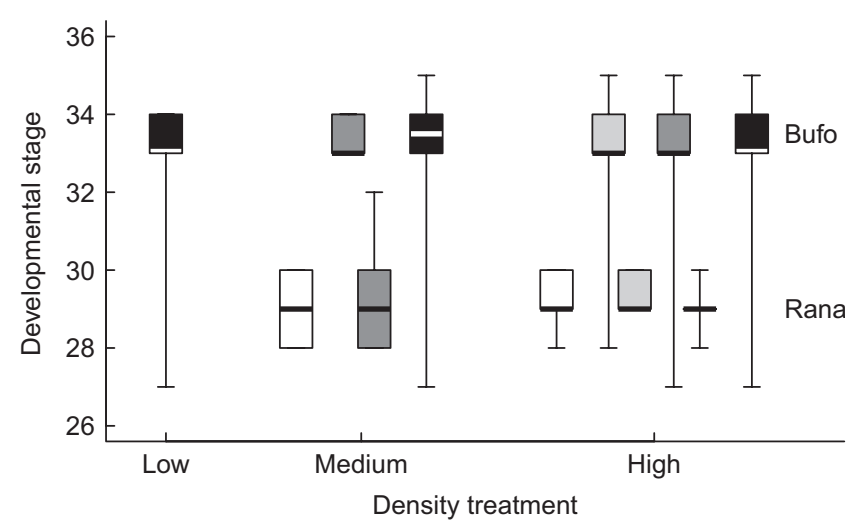

FIGURE 2 Developmental stage of Bufo (upper boxes) and Rana (lower boxes) tadpoles in the eight treatment groups. In each box plot, the thick middle line, box and whiskers represent the median, interquartile range and data range respectively. Box colour denotes the tubs' species composition as explained in Figure 1a (black: Bufo only, white: Rana only; dark grey: both species, more Bufo than Rana; light grey: both species, fewer Bufo than Rana)

corroborates our earlier finding that the toxin content of common toad tadpoles correlated positively with the density of competitors across natural ponds (Bókony et al., 2016). Such correlation may arise either by local adaptation in constitutive defences or via phenotypic plasticity (Bókony et al., 2016); our present results support the latter explanation. Furthermore, in another laboratory experiment, we found that the bufadienolide amount of common toad tadpoles increased when competition was simulated by decreasing food availability for small groups of tadpoles at a single density (Üveges et al., 2017). Although this might have been a stress response to hunger irrespective of competition, our present results clearly demonstrate that increased bufadienolide production is induced by competition even when food is relatively abundant (i.e. mortality was negligible). In both of our experiments, tadpoles reared in more competitive environments attained smaller body mass, but in spite of this inhibited growth, their total bufadienolide levels were at least as high or even higher compared to tadpoles reared in less competitive environments (Üveges et al., 2017; figure 1e,f in the present study). This suggests that competing tadpoles invested their resources into toxin production at the expense of growth; or alternatively, they may have been able to maintain or even increase their bufadienolide levels despite food limitation because the costs of bufadienolide synthesis may be low in terms of dietary resources (Kurali, Pásztor, Hettyey, \& Tóth, 2016; Üveges et al., 2017). It is possible, however, that induced bufadienolide synthesis is traded off against long-term investment into critical life-history traits, as suggested by earlier studies (Benard \& Fordyce, 2003; Hagman et al., 2009).

Although we found competition-induced changes in the bufadienolide content of Bufo tadpoles, the role of these chemicals in allelopathy remains unclear. We expected that bufadienolides would mainly be induced by, and effective against, heterospecific competitors because toxin-producing species should have evolved protection from autotoxicity; for example, consuming the bufadienolide-rich eggs or tissues of cane toads Rhinella marina has no ill effect on conspecific tadpoles but kills other species (Crossland \& Shine, 2012; Crossland et al., 2011). However, in the common toad-agile frog system, we found no indication that interspecific competition would be the specific driver of toxin production. Bufo tadpoles' bufadienolide levels were not increased by the presence of Rana tadpoles more than by the same total mass of conspecific competitors, and the presence of Bufo larvae did not reduce the growth and development of Rana larvae. It is unlikely that the tadpoles could not discriminate between conspecific and heterospecific competitors (Relyea, 2002). Instead, a possible explanation for the lack of interspecific effects is that the encounter rate between the two species may have been relatively low, because Bufo larvae are more active and more gregarious than Rana larvae (our pers. obs.). If Bufo tadpoles use proximity or physical interaction (e.g. visual and tactile cues) for assessing competitor density (Rot-Nikcevic, Denver, \& Wassersug, 2005) to adjust their toxin production, they will have perceived stronger competition by conspecifics than by Rana tadpoles. Low encounter rates might also explain the lack of allelopathic effects on Rana tadpoles, because bufadienolides are amphiphilic molecules so their highest concentrations are likely to occur at the interface of tadpole skin and water (Kubanek et al., 2002). In this case, allelopathy would become important only at very high interspecific encounter rates, e.g. when water depth is low due to desiccation (Cabrera-Guzmán, Crossland, \& Shine, 2013), or at very low food availability which may increase the importance of scavenging on injured or dead toad tadpoles (Jefferson, Hobson, \& Chivers, 2014; Jordan, Rombough, Pearl, \& McCreary, 2004; Mahapatra, Dutta, \& Sahoo, 2017; Wildy, Chivers, Kiesecker, \& Blaustein, 2001).

Response surface analysis indicated that intraspecific competition had stronger effects on bufadienolide production than interspecific competition did, and high competitor biomass increased the total bufadienolide amount only when the majority of the competitors were conspecifics. This suggests that an important function of the inducibility of toxin production may be to mitigate some risk posed primarily by conspecifics; we propose two, mutually non-exclusive hypotheses. First, high densities and low per capita food levels are known to increase the incidence of intraspecific aggression and cannibalism in amphibian larvae (Jefferson et al., 2014; Jordan et al., 2004; Mahapatra et al., 2017; Wildy et al., 2001), and elevated bufadienolide levels might prevent or mitigate intraspecific biting by deterring conspecific attacks. Although toads are tolerant to the toxins of their own species (Crossland \& Shine, 2011; Crossland et al., 2011), they still might find these substances distasteful as do many other species (Gunzburger \& Travis, 2005). Alternatively, toad toxins may function in intraspecific chemical communication and species recognition (Crossland \& Shine, 2011; Hagman \& Shine, 2009), and thereby might help preventing cannibalistic attempts against kin in sibling schools which are characteristic of toad larvae (Blaustein, 1988).

The second possible function of competitor-induced chemical defence is the prevention of disease. Bufadienolides are known to have antimicrobial effects (Cunha Filho et al., 2005; Tempone et al., 2008), so they may be an important component of immune defence in toads which lack the antimicrobial skin peptides that are found in many other amphibians (Conlon, Iwamuro, \& King, 2009). Infection risk can induce chemical defences, for example in leopard frog Lithobates pipiens 
tadpoles, doubling the density of conspecifics caused more than $250 \%$ increase in skin peptides (Groner et al., 2014). Because the chances of transmitting parasites or pathogens are likely to be higher at high densities (Briggs, Knapp, \& Vredenburg, 2010), and individuals are more likely to be susceptible to the diseases of conspecifics than other species (Freeland, 1983), our results are in concordance with the hypothesis that tadpoles produce more bufadienolides in response to elevated infection risk. It remains to be tested whether the upregulated bufadienolide production is effective in preventing disease transmission and/or cannibalistic interactions.

In sum, our results demonstrate that a form of chemical defence, considered to have evolved to provide protection against predators, can be induced by competitors. Although we found no indication of interspecific allelopathic effects, the potential of bufadienolides to mitigate infection risk and/or to prevent cannibalism makes them ideal candidates for multi-purpose allomones. So far, theoretical and empirical studies of inducible defences have, by far the most frequently, focused on the effects of predators (Tollrian \& Harvell, 1999); the time is ripe for addressing the role of defensive and/or offensive chemicals against multiple enemies, and the consequences thereof for resource allocation trade-offs, life-history evolution and responses to anthropogenic change (Bókony, Mikó, et al., 2017; Hettyey et al., 2014).

\section{ACKNOWLEDGEMENTS}

We thank Zs. Mikó, A. Kurali, S. Orf, T. Sendula and M. Szederkényi for their help during the experiment. Funding was provided by the Lendület programme of the Hungarian Academy of Sciences (MTA, LP2012-24/2012), an FP7 Marie Curie Career Integration Grant (PCIG13-GA-2013-631722), and the National Research, Development and Innovation Office (NKFIH) of Hungary (grant no. 115402). V.B. was supported by the János Bolyai Scholarship of the Hungarian Academy of Sciences. B.Ü. was supported by the Young Researcher programme of the Hungarian Academy of Sciences.

\section{AUTHORS' CONTRIBUTIONS}

A.H., B.Ü. and V.B. designed the experiment, B.Ü. performed the experiments, Á.M.M. performed the HPLC analyses; V.B. conducted the statistical analyses and led the writing of the manuscript. All authors contributed critically to the drafts and gave final approval for publication.

\section{DATA ACCESSIBILITY}

Data deposited in the Dryad Digital Repository https://doi. org/10.5061/dryad.q3g70 (Bókony, Üveges, et al., 2017).

\section{ORCID}

Veronika Bókony (iD http://orcid.org/0000-0002-2136-5346

Bálint Üveges iD http://orcid.org/0000-0001-9234-9258
Attila Hettyey (iD http://orcid.org/0000-0003-0678-0936

\section{REFERENCES}

Adams, E. S., \& Traniello, J. F. A. (1981). Chemical interference competition by Monomorium minimum (Hymenoptera: Formicidae). Oecologia, 51, 265-270.

Adler, F. R., \& Harvell, C. D. (1990). Inducible defenses, phenotypic variability and biotic environments. Trends in Ecology and Evolution, 5, 407-410.

Alford, R. A., \& Wilbur, H. M. (1985). Priority effects in experimental pond communities: responses of Hyla to Bufo and Rana. Ecology, 66, 1106-1114.

Bardsley, L., \& Beebee, T. J. (2001). Non-behavioural interference competition between anuran larvae under semi-natural conditions. Oecologia, 128, 360-367.

Benard, M. F., \& Fordyce, J. A. (2003). Are induced defenses costly? Consequences of predator-induced defenses in western toads, Bufo boreas. Ecology, 84, 68-78.

Berenbaum, M. R. (1995). The chemistry of defense: theory and practice. Proceedings of the National Academy of Sciences of the United States of America, 92, 2-8.

Blaustein, A. R. (1988). Ecological correlates and potential functions of kin recognition and kin association in anuran larvae. Behavior Genetics, 18, 449-464.

Bókony, V., Mikó, Z., Móricz, Á. M., Krüzselyi, D., \& Hettyey, A. (2017). Chronic exposure to a glyphosate-based herbicide makes toad larvae more toxic. Proceedings of the Royal Society B, 284, 20170493.

Bókony, V., Móricz, Á. M., Tóth, Z., Gál, Z., Kurali, A., Mikó, Z., ... Hettyey, A. (2016). Variation in chemical defense among natural populations of common toad, Bufo bufo, tadpoles: The role of environmental factors. Journal of Chemical Ecology, 42, 329-338.

Bókony, V., Üveges, B., Móricz, Á., \& Hettyey, A. (2017). Data from: Competition induces increased toxin production in toad larvae without allelopathic effects on heterospecific tadpoles. Dryad Digital Repository, https://doi.org/10.5061/dryad.q3g70

Briggs, C. J., Knapp, R. A., \& Vredenburg, V. T. (2010). Enzootic and epizootic dynamics of the chytrid fungal pathogen of amphibians. Proceedings of the National Academy of Sciences of the United States of America, 107, 9695-9700.

Brodie, E. D. (2009). Toxins and venoms. Current Biology, 19, R931-R935.

Cabrera-Guzmán, E., Crossland, M. R., \& Shine, R. (2013). Competing tadpoles: Australian native frogs affect invasive cane toads (Rhinella marina) in natural waterbodies. Austral Ecology, 38, 896-904.

Casewell, N. R., Wüster, W., Vonk, F. J., Harrison, R. A., \& Fry, B. G. (2013). Complex cocktails: The evolutionary novelty of venoms. Trends in Ecology and Evolution, 28, 219-229.

Conlon, J. M., Iwamuro, S., \& King, J. D. (2009). Dermal cytolytic peptides and the system of innate immunity in anurans. Annals of the New York Academy of Sciences, 1163, 75-82.

Connell, J. H. (1983). On the prevalence and relative importance of interspecific competition: Evidence from field experiments. The American Naturalist, 122, 661-696.

Crossland, M., Brown, G., \& Shine, R. (2011). The enduring toxicity of roadkilled cane toads (Rhinella marina). Biological Invasions, 13, 2135-2145.

Crossland, M. R., \& Shine, R. (2011). Cues for cannibalism: Cane toad tadpoles use chemical signals to locate and consume conspecific eggs. Oikos, 120, 327-332.

Crossland, M. R., \& Shine, R. (2012). Embryonic exposure to conspecific chemicals suppresses cane toad growth and survival. Biology Letters, 8, 226-229.

Cunha Filho, G. A., Schwartz, C. A., Resck, I. S., Murta, M. M., Lemos, S. S., Castro, M. S., ... Schwartz, E. F. (2005). Antimicrobial activity of the bufadienolides marinobufagin and telocinobufagin isolated as major 
components from skin secretion of the toad Bufo rubescens. Toxicon, 45, 777-782.

Gosner, K. L. (1960). A simplified table for staging anuran embryos and larvae with notes on identification. Herpetologica, 16, 183-190.

Freeland, W. J. (1983). Parasites and the coexistence of animal host species. The American Naturalist, 121, 223-236.

Griffiths, R. A., Denton, J., \& Wong, A. L.-C. (1993). The effect of food level on competition in tadpoles: Interference mediated by protothecan algae? Journal of Animal Ecology, 62, 274-279.

Groner, M. L., Rollins-Smith, L. A., Reinert, L. K., Hempel, J., Bier, M. E., \& Relyea, R. A. (2014). Interactive effects of competition and predator cues on immune responses of leopard frogs at metamorphosis. Journal of Experimental Biology, 217, 351-358.

Gunzburger, M., \& Travis, J. (2005). Critical literature review of the evidence for unpalatability of amphibian eggs and larvae. Journal of Herpetology, 39, 547-571.

Gurevitch, J., Morrow, L. L., Wallace, A., \& Walsh, J. S. (1992). A metaanalysis of competition in field experiments. The American Naturalist, 140, 539-572.

Hagman, M., Hayes, R. A., Capon, R. J., \& Shine, R. (2009). Alarm cues experienced by cane toad tadpoles affect post-metamorphic morphology and chemical defences. Functional Ecology, 23, 126-132.

Hagman, M., \& Shine, R. (2009). Species-specific communication systems in an introduced toad compared with native frogs in Australia. Aquatic Conservation: Marine and Freshwater Ecosystems, 19, 724-728.

Henrikson, B. (1990). Predation on amphibian eggs and tadpoles by common predators in acidified lakes. Ecography, 13, 201-206.

Hettyey, A., Török, J., \& Kovács, T. (2003). Hét kétéltűfaj szaporodásbiológája és élőhelyhasználata a Visegrádi-hegység területén. Állattani Közlemények, 88, 41-55.

Hettyey, A., Tóth, Z., \& Van Buskirk, J. (2014). Inducible chemical defences in animals. Oikos, 123, 1025-1028.

Hettyey, A., Vincze, K., Zsarnóczai, S., Hoi, H., \& Laurila, A. (2011). Costs and benefits of defences induced by predators differing in dangerousness. Journal of Evolutionary Biology, 24, 1007-1019.

Inouye, B. D. (2001). Response surface experimental designs for investigating interspecific competition. Ecology, 82, 2696-2706.

Jefferson, D. M., Hobson, K. A., \& Chivers, D. P. (2014). Time to feed: How diet, competition, and experience may influence feeding behaviour and cannibalism in wood frog tadpoles Lithobates sylvaticus. Current Zoology, 60, 571-580.

Jordan, D. J., Rombough, C. J., Pearl, C. A., \& McCreary, B. (2004). Cannibalism and predation by Western toad (Bufo boreas boreas) larvae in Oregon, USA. Western North American Naturalist, 64, 403-405.

Kubanek, J., Whalen, K. E., Engel, S., Kelly, S. R., Henkel, T. P., Fenical, W., \& Pawlik, J. R. (2002). Multiple defensive roles for triterpene glycosides from two Caribbean sponges. Oecologia, 131, 125-136.

Kurali, A., Pásztor, K., Hettyey, A., \& Tóth, Z. (2016). Toxin depletion has no effect on antipredator responses in common toad (Bufo bufo) tadpoles. Biological Journal of the Linnean Society, 119, 1000-1010.

Lardner, B. (2000). Morphological and life history responses to predators in larvae of seven anurans. Oikos, 88, 169-180.

Licht, L. E. (1967). Growth inhibition in crowded tadpoles: Intraspecific and interspecific effects. Ecological Monographs, 48, 736-745.

Mahapatra, S., Dutta, S. K., \& Sahoo, G. (2017). Opportunistic predatory behaviour in Duttaphrynus melanostictus (Schneider, 1799) tadpoles. Current Science, 112, 1755-1760.

McDiarmid, R., \& Altig, R. (1999). Tadpoles: The biology of anuran larvae. Chicago, IL: University of Chicago Press.

Mikó, Z., Ujszegi, J., Gál, Z., Imrei, Z., \& Hettyey, A. (2015). Choice of experimental venue matters in ecotoxicology studies: Comparison of a laboratory-based and an outdoor mesocosm experiment. Aquatic Toxicology, 167, 20-30.
Pike, N. (2011). Using false discovery rates for multiple comparisons in ecology and evolution. Methods in Ecology and Evolution, 2, 278-282.

Ramamonjisoa, N., \& Natuhara, Y. (2017). Hierarchical competitive ability and phenotypic investments in prey: Inferior competitors compete and defend. Journal of Zoology, 301, 157-164.

Reigosa, M. J., Pedrol, N., \& González, L. (2006). Allelopathy: A physiological process with ecological implications. Dordrecht, the Netherlands: Springer.

Relyea, R. A. (2002). Competitor-induced plasticity in tadpoles: Consequences, cues, and connections to predator-induced plasticity. Ecological Monographs, 72, 523-540.

Relyea, R. A., \& Auld, J. R. (2004). Having the guts to compete: How intestinal plasticity explains costs of inducible defences. Ecology Letters, 7 , 869-875.

Relyea, R. A., \& Auld, J. R. (2005). Predator- and competitor-induced plasticity: How changes in foraging morphology affect phenotypic tradeoffs. Ecology, 86, 1723-1729.

Rot-Nikcevic, I., Denver, R. J., \& Wassersug, R. J. (2005). The influence of visual and tactile stimulation on growth and metamorphosis in anuran larvae. Functional Ecology, 19, 1008-1016.

Siemens, D. H., Garner, S. H., Mitchell-Olds, T., \& Callaway, R. M. (2002). Cost of defense in the context of plant competition: Brassica rapa may grow and defend. Ecology, 83, 505-517.

Tempone, A. G., Pimenta, D. C., Lebrun, I., Sartorelli, P., Taniwaki, N. N., de Andrade, H. F., ... Jared, C. (2008). Antileishmanial and antitrypanosomal activity of bufadienolides isolated from the toad Rhinella jimi parotoid macrogland secretion. Toxicon, 52, 13-21.

Tollrian, R., \& Harvell, C. D. (1999). The ecology and evolution of inducible defenses. Princeton, NJ: Princeton University Press.

Üveges, B., Fera, G., Móricz, Á. M., Krüzselyi, D., Bókony, V., \& Hettyey, A. (2017). Age- and environment-dependent changes in chemical defences of larval and post-metamorphic toads. BMC Evolutionary Biology, $17,173$.

Vági, B., Kovács, T., Băncilă, R., Hartel, T., \& Anthony, B. P. (2013). A landscape-level study on the breeding site characteristics of ten amphibian species in Central Europe. Amphibia-Reptilia, 34, 63-73.

Van Buskirk, J. (2002). A comparative test of the adaptive plasticity hypothesis: Relationships between habitat and phenotype in anuran larvae. The American Naturalist, 160, 87-102.

Wells, K. D. (2007). The ecology and behavior of amphibians. Chicago, IL: University of Chicago Press.

Wildy, E. L., Chivers, D. P., Kiesecker, J. M., \& Blaustein, A. R. (2001). The effects of food level and conspecific density on biting and cannibalism in larval long-toed salamanders, Ambystoma macrodactylum. Oecologia, 128, 202-209.

Zuur, A. F., leno, E. N., Walker, N. J., Saveliev, A. A., \& Smith, G. M. (2009). Mixed effects models and extensions in ecology with R. New York, NY: Springer.

\section{SUPPORTING INFORMATION}

Additional Supporting Information may be found online in the supporting information tab for this article.

How to cite this article: Bókony V, Üveges B, Móricz ÁM, Hettyey A. Competition induces increased toxin production in toad larvae without allelopathic effects on heterospecific tadpoles. Funct Ecol. 2017;00:1-9. https://doi.org/10.1111/1365-2435.12994 